Article

\title{
The Safety Journey: Using a Safety Maturity Model for Safety Planning and Assurance in the UK Coal Mining Industry
}

\author{
Patrick Foster ${ }^{1, *}$ and Stuart Hoult ${ }^{2}$ \\ 1 Camborne School of Mines, University of Exeter, Cornwall Campus, Penryn, Cornwall TR10 9EZ, UK \\ 2 UK Coal Plc, Harworth Park, Blyth Road, Harworth, Doncaster, South Yorkshire DN11 8DB, UK; \\ E-Mail: SHoult@ukcoal.com
}

* Author to whom correspondence should be addressed; E-Mail: P.J.Foster@exeter.ac.uk; Tel.: +44-1326-371828; Fax: +44-1326-371859.

Received: 30 November 2012; in revised form: 30 January 2013 / Accepted: 1 February 2013 / Published: 18 February 2013

\begin{abstract}
A Safety Maturity Model was developed for use in UK coal mining operations in order to assess the level of compliance and effectiveness with a recently introduced standards based safety management system. The developed model allowed for a "self-assessment" of the maturity to be undertaken by teams from the individual sites. Assessments were undertaken at all sites (surface and underground) and in some cases within each site (e.g., underground operations, surface coal preparation plant). Once the level of maturity was established, improvement plans were developed to improve the maturity of individual standards that were weaker than the average and/or improve the maturity as a whole. The model was likened to a journey as there was a strong focus on continual improvement and effectiveness of the standards, rather than pure compliance. The model has been found to be a practical and useful tool by sites as a means of identifying strengths and weaknesses within their systems, and as a means of assurance with the safety management system standards.
\end{abstract}

Keywords: safety culture; safety management systems; safety maturity

\section{Introduction}

The maturity model concept is a recent research innovation within the discipline of safety management and has been applied to safety culture development within a number of "high hazard" 
industries such as the offshore [1,2], aviation [3], rail [4,5] and petro-chemical industries [6,7]. These models originated from both quality and organizational development models as well as capability maturity models that had been used in the software industry [7]. Such models were developed to allow organizations to understand their own level of safety culture maturity by assessing the level of compliance with various key elements of safety culture across a number of stages (typically 5) that represent different levels of maturity.

Industries where these models are well established, such as the oil and gas industry, are currently putting a considerable amount of effort into establishing best practice and identifying tools and techniques that are proven to be effective in improving safety [1]. Whilst this approach is sensible, its effectiveness may be limited by differences in the safety culture across and within the industry, and those companies/sites in the early stages of developing their culture will require different techniques that those with stronger cultures. Safety maturity models, which can be applied on a company by company, or site by site basis, can identify these differences and then help address any behavioral and cultural issues they may have with a view to improving the safety culture maturity over time.

\section{Safety Maturity Models}

An example of a safety maturity model is given by Fleming and Lardner [8] who show a three stage model developed by an offshore operating company. The three stages of safety culture in this model are (i) dependent, (ii) independent and (iii) interdependent. In a "dependent culture" there is an emphasis on management and supervisory control, with a heavy focus on written rules and procedures. Their study [8] states that if an organization with such a culture wants to improve its maturity it needs to develop an "independent culture" where the focus is on a personal commitment to and responsibility for safety. Whilst there will still be rules and standards, employees look after their own safety. The final stage is "interdependent" where there is a team commitment to safety with everyone having a sense of responsibility for safety beyond their own work and by caring for the safety of others. In this model, the drivers of the safety culture improvement process are teamwork, trust and the ownership of safety by the workforce. The same stages and drivers are defined by DuPont's "Bradley Curve".

Two of the more common cited maturity models are those subsequently developed by Fleming $[1,6]$ and that of Hudson [2,9,10]. Fleming's model [1] looks at the level of maturity across 10 elements of safety culture adapted from those listed by the UK Health and Safety Executive in their human error guidance, HSG48 [11] namely:

- Management commitment and visibility;

- Communications;

- $\quad$ Production versus Safety;

- Learning organization;

- Safety resources;

- Participation;

- Shaded perceptions about safety;

- Trust;

- Individual relations and job satisfaction. 
The five levels of maturity are set out as a number of iterative stages that an organisation can move through. These stages of maturity are (i) Emerging, (ii) Managing, (iii) Involving, (iv) Co-operating and (v) Continually Improving; and the model provides a framework to assist in the selection and implementation of appropriate behavioral interventions. The overall level of safety culture maturity is determined by taking a mean of the level of maturity at each of these individual ten elements. The model suggests that a stage by stage approach in improving safety culture is required and that skipping a stage in the sequence is difficult [1]. It is likely that a site will spend some time, perhaps years, successfully progressing from one stage to the next. This safety culture improvement process is undertaken by sites assessing their current level of maturity and then by developing and implementing a plan to move to the next level based on removing the weaknesses of the previous level [12]. The implementation of this plan is monitored and the level of maturity re-assessed to evaluate success and any further actions.

The maturity refers to the maturity of the organization's behaviors and not the maturity of the safety management systems. Therefore Fleming [1] also states that his model is only really of relevance to organizations where the technical and systems aspects of safety are performing adequately and the majority of accidents that occur appear to be due to behavioral or cultural factors. Lardner [6] gives a case study of the use of this model at a large petrochemical plant in the UK where the maturity of most of the individual safety culture elements were at level 3 (Involving) moving to level 4 (Co-operating) indicating a mature culture but wary of some differences in culture across different occupational groups.

Hudson's Model $[2,9,10]$ has been used to describe the safety maturity in many industries including oil, aviation and healthcare. Hudson's model illustrates a five step progression from a "pathological" stage where there is a "no care" culture and "no systems" through to a "generative" stage where managing risks is a way of life and fully integrated systems are effectively in place. The descriptions of each stage of safety culture are given below [7,9].

- Pathological—Safety is a problem caused by workers. The main drivers are the business and a desire not to get caught by the regulator.

- Reactive-Organisations start to take safety seriously but there is only action after incidents.

- Calculative - Safety is driven by management systems, with much collection of data. Safety is still primarily driven by management and imposed rather than looked for by the workforce.

- Proactive-With improved performance, the unexpected is a challenge. Workforce involvement starts to move the initiative away from a purely top down approach.

- Generative-There is active participation at all levels. Safety is perceived to be an inherent part of the business. Organisations are characterised by chronic unease as a counter to complacency.

Parker et al. [10] developed a framework consisting of 18 elements, and developed a question set relating to each element and each maturity level. This gave rise to a tool that could be used by organizations to understand their safety culture maturity. These eighteen elements were classed as either concrete elements [i.e., relating to the safety management system (11 elements in total)] or abstract elements [i.e., relating to the attitudes and behaviors ( 7 elements in total)]. Therefore this model could be applied to organizations with weaker safety management systems unlike Flemings' model [1]. The eighteen elements used are given in Table 1. 
Table 1. Elements of safety culture within Hudson maturity model [10].

\begin{tabular}{|c|c|}
\hline "Concrete" Elements & "Abstract" Elements \\
\hline Benchmarking, Trends \& Statistics & Who causes accidents in the eyes of management? \\
\hline Audits \& Reviews & What happens after an accident? Is the feedback Loop \\
\hline Incident/Accident Reporting, Investigation \& Analysis; & being closed? \\
\hline Hazard and Unsafe Act reports & How do safety meetings feel? \\
\hline Work planning including PTW, Journey Management & Balance between HSE \& Profitability? \\
\hline Contractor Management & Is management interested in communicating HSE issues \\
\hline Competency/Training & with the workforce? \\
\hline Work-site Job Safety Techniques & Commitment level of the workforce and level of care \\
\hline Who Checks Safety on a day to day basis? & for colleagues. \\
\hline What is size \& status of the HSE Department? & What is the purpose of procedures? \\
\hline What are the rewards of good safety performance? & \\
\hline
\end{tabular}

\section{The Use of Safety Maturity Models in the Mining Industry}

Within the mining industry there are many differences in safety culture and the state of safety management across operations which will limit the effectiveness of best practice tools and techniques that companies are trying to introduce. Like the oil industry, sites at the early stages of safety maturity will require different techniques that those with stronger maturities. Mining is therefore well suited to the use of maturity models and indeed, some have been developed and used.

A team from the University of Queensland developed the MIRM (Minerals Industry Risk Management) Maturity Chart that was based on both the Hudson model and a similar approach used by Bayside Aluminum, a BHP Billiton site in Richards Bay, South Africa [13-15]. The MIRM model is described as a ladder that has five stages or "rungs". The terms used are slightly different from those used by Hudson [2,9] although the implied levels of maturity are similar. The lowest rung is called "Vulnerable" where the site will "accept that accidents happen". The next rung or level of improvement sees the site move to "Reactive" where there is recognition that the site should "prevent a similar incident". Improvement from this rung moves the site to "Compliant" where the culture and systems try to "prevent incidents before they occur". The next rung in the ladder is probably the largest or most profound step for any site. Movement to the "Proactive" rung involves the site, through its culture and methods, embracing the systems approach. At this rung of the ladder the system ownership genuinely moves to line management and supervision. The final rung in the MIRM ladder is titled "Resilient" which is used to describe a site that has successfully integrated safety and risk management into its operations. The rungs are shown in Figure 1, along with the specific characteristics expected at each stage.

The MIRM ladder was not written as a guideline but rather a description of a journey that is intended to fit any minerals industry site. It has been provided to assist sites with identifying their current status on this journey and potential next steps for improvement. Like the Hudson model there is a clear distinction between the cultural elements and the system elements. 
Figure 1. MIRM maturity chart [15].

\begin{tabular}{|c|c|c|c|c|}
\hline \multicolumn{5}{|c|}{ Minerals Industry Risk Management (MIRM) Maturity Chart } \\
\hline 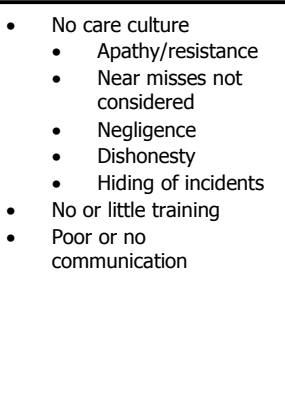 & $\begin{array}{l}\text { Blame culture } \\
\text { Accept need to care } \\
\text { Some near miss } \\
\text { reporting } \\
\text { - Some window dressing } \\
\text { e.g. pre-inspection } \\
\text { cleanups and light duty } \\
\text { Disciplinary action } \\
\text { Minimum / inconsistent } \\
\text { training } \\
\text { Some communication on a } \\
\text { need to know basis }\end{array}$ & 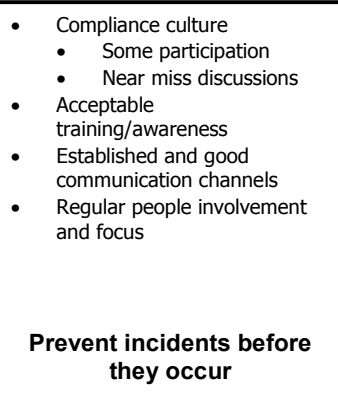 & $\begin{array}{l}\text { - Ownership culture } \\
\text { - Involvement at all levels } \\
\text { - Near miss involvement } \\
\text { High level of } \\
\text { training/awareness } \\
\text { Communication at a high level } \\
\text { hiding nothing }\end{array}$ & $\begin{array}{l}\text { - Way of life } \\
\text { Comes natural } \\
\text { Personal } \\
\text { involvement by all } \\
\text { to prevent } \\
\text { incidents } \\
\text { Complete understanding } \\
\text { All informed at all times } \\
\text { about everything } \\
\text { Way we do business }\end{array}$ \\
\hline 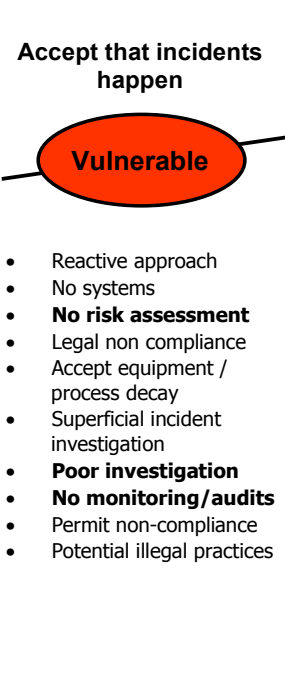 & $\begin{array}{l}\text { - Administrator driven } \\
\text { - } \text { Loose systems, elements of a } \\
\text { - RS Management System } \\
\text { assesstive risk } \\
\text { - Minimum legal compliance } \\
\text { - Apply PPE as a way of } \\
\text { eliminating exposure } \\
\text { Incident investigation } \\
\text { but limited analysis } \\
\text { - Focus on what } \\
\text { happened } \\
\text { - Ho systems focus } \\
\text { Ad homan fault focus } \\
\text { audits } \\
\text { - No occunitoring/ } \\
\text { health initianatives hygiene or } \\
\text { - Reactive medical monitoring } \\
\text { Monitoring as per regulations }\end{array}$ & $\begin{array}{ll}\text { - } & \text { OH\&S Coord. driven } \\
\text { OH\&S stds system and ISO } \\
9002 \text { or equivalent } \\
\text { - } \text { Risk assessment through } \\
\text { existing systems } \\
\text { - } \quad \text { Total legal compliance } \\
\text { - Strictly enforce the use of PPE } \\
\text { where required (knowing risk) } \\
\text { Causal incident analysis } \\
\text { based on event potential } \\
\text { - Info sharing from events } \\
\text { Planned occupational hygiene } \\
\text { / environmental monitoring } \\
\text { - Periodical medical } \\
\text { - examinations } \\
\text { Planned } \\
\text { monitoring/audits } \\
\text { - Safety meetings \& talks } \\
\text { Some task observations }\end{array}$ & $\begin{array}{ll}\text { - Line driven systems } \\
\text { improvement } \\
\text { - ISO } 14001 \text { and OHSAS } 18000 \\
\text { or equivalent } \\
\text { - Pro-active formal risk } \\
\text { assmt } \\
\text { - Beyond legal compliance } \\
\text { - Seek to actively engineer out } \\
\text { process/equipment } \\
\text { inadequacies } \\
\text { - Incident learnings shared } \\
\text { with all levels } \\
\text { - Well designed plans/procedures } \\
\text { - } \begin{array}{l}\text { Focus on adhering to site } \\
\text { plans and procedures }\end{array} \\
\text { - Integrated audits } \\
\text { - Peer evaluation and discussion }\end{array}$ & $\begin{array}{ll}\text { - } & \text { Individually internalised } \\
\text { Integrated management } & \text { systems } \\
\text { - } & \text { Risk assessment } \\
\text { integrated into all } \\
\text { systems } \\
\text { - Self regulating style } \\
\text { - } & \text { Eliminate problems } \\
\text { before they occur } \\
\text { - } & \text { All threats considered in } \\
\text { decision-making } \\
\text { - Systems } \\
\text { enhancement } \\
\text { through external } \\
\text { evaluation / auditing }\end{array}$ \\
\hline
\end{tabular}

In 2007, Anglo American plc embarked on a major new in-house initiative in order to revitalize and strengthen the companies approach to safety risk management and a major training programme was developed that was delivered to all their Managers worldwide [11,16]. As part of this training, the risk management process was explained and discussed as a "journey" based on the MIRM safety ladder that involves both people and systems [16]. Figure 2 shows their model depicted as an image of a spiral staircase that is used in all courses, with discussions and exercises to identify current status and plans to improve. Here assessments are made against 23 elements (6 people elements and 17 system elements).

As part of this roll-out, all management teams have undertaken an assessment of where they are on the "safety journey" and plans have been developed for improvement that have been integrated into their operations.

It is important to note that these models are not just about assessing safety culture on its own. The Anglo Model, MIRM Ladder and Hudson Model all suggest a strong relationship between the culture of an organization and the development of a systems approach. It is critical to recognize that systems cannot progress up the ladder without culture progressing in parallel and vice versa. Gordon et al. [3] states that if there is a safety management system but no real commitment or culture towards safety, then the management system will not be effective, as decisions will not prioritise safety. Similarly, if there is a good safety culture, but no management system, then the way that safety is organized may be inconsistent, under-resourced and not seen as business driven [3]. It is possible that systems effectiveness issues that are currently experienced at mines sites are a result of such a culture/systems mismatch. 
Figure 2. Anglo American Plc maturity model [16].
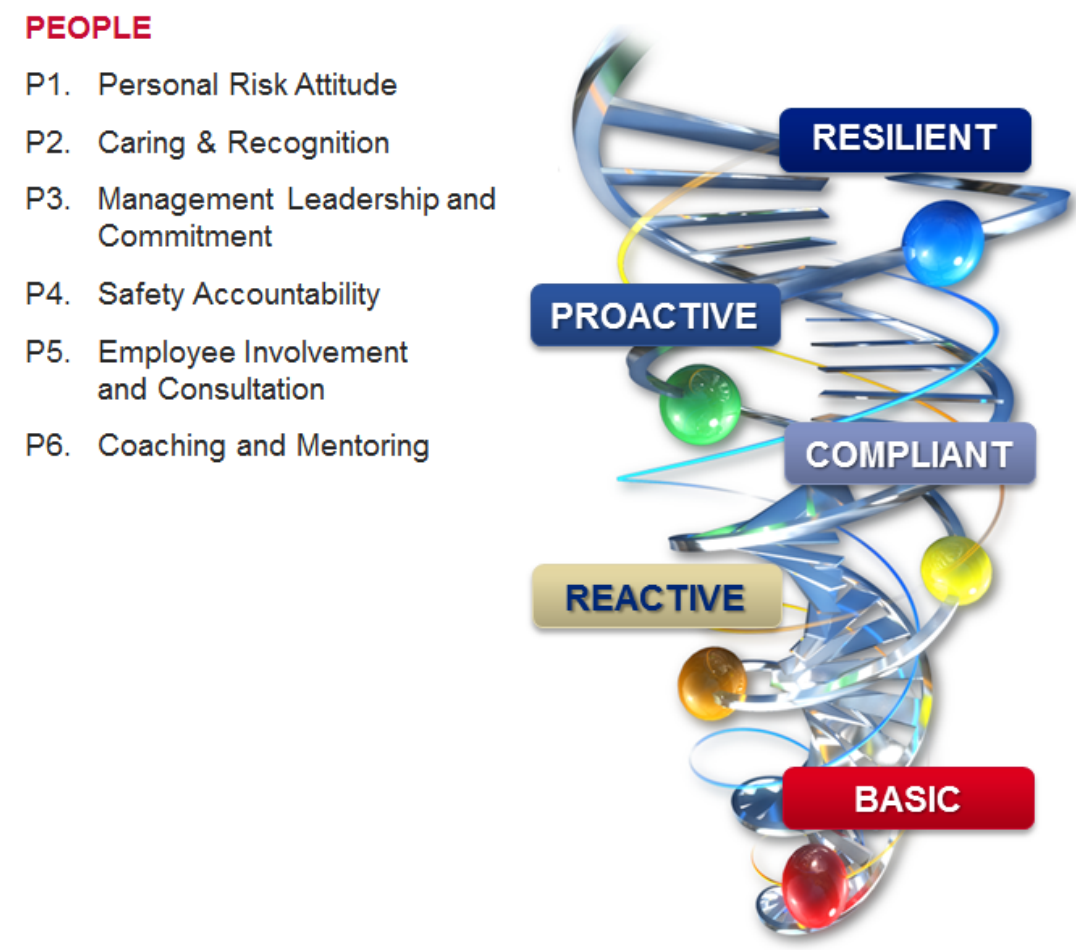

\author{
SYSTEMS \\ S1. Risk Management Adoption \\ S2. Strategic Planning \\ S3. Project \& Process Design \\ Management \\ S4. Major Hazard/Priority Risk \\ Identification and Management \\ S5. Change Management \\ S6. Job and Task Planning \\ S7. Hazard Identification and Reporting \\ S8. Training and Competency \\ s9. Communications \\ S10. Knowledge Management \\ S11. Maintenance \\ S12. Procurement \\ S13. Contractor Management \\ S14. Incident Investigation and Analysis \\ S15. Emergency Response \\ S16. Safety Performance Measurement \\ S17. Auditing and Monitoring
}

\section{Development of a Safety Maturity Model for UK Coal}

\subsection{The UK Coal Safety Way}

By global standards UK Coal plc is a small mining company that took over many of the operating surface and deep mines when the UK coal industry was privatized in 1995. Although at the time of privatization it operated 20 deep mines and 27 surface mines in the UK, there has been a gradual reduction over the last 16 years to a point where it currently operates 3 deep mines and 6 surface mines. UK Coal remains the largest indigenous producer of coal in the UK, supplying approximately $5 \%$ of the total country's energy needs for electricity generation [17].

Although the mining industry in the UK is largely in decline, what has become increasingly obvious was the overall safety performance within the sector which appeared to be on a worsening trend. This period saw UK Coal's safety performance dip, from a period of almost seven years without a fatal accident, to a position where there were seven fatal accidents in deep mines between 2006 and 2009. This was accompanied by an increase in the level of significant incidents. In 2009 decisions were made to start and address the decline in safety performance, and in 2010 a new safety management system was introduced. This drew on best practices from other major mining companies, and other heavy industry. The revised management system was designed consisting of twelve standards (see Figure 3). Within each of the twelve elements a series of requirements had been formulated which needed to be adopted by all sites.

Whilst it was necessary to assess compliance against those standards, it was felt that any means of assurance should not just measure pure compliance as a "yes" or "no". It was necessary to incorporate a process that would give individual sites and departments targeted development areas to drive a continuous safety improvement down throughout the organization above and beyond pure compliance. 
It was felt that a "maturity model" approach would best suit this as it would highlight strong and weak areas and by considering it as a "journey", it would allow for continual improvement.

Figure 3. The UK Coal safety management system.

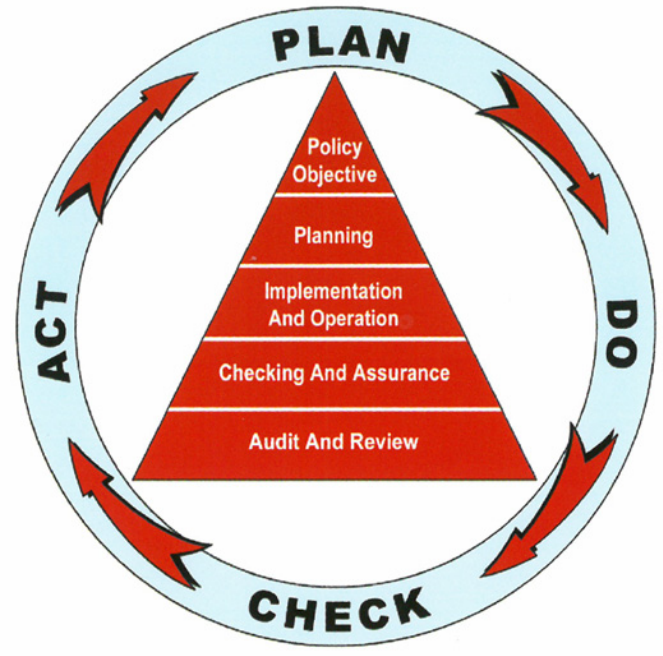

1. Leadership and Accountability.

2. Policy and Commitment.

3. Risk and Change Management.

4. Legal and other requirement.

5. Objectives, Targets and Performance.

6. Management.

7. Training, Competence and Awareness.

8. Communication and Consultation.

9. Control of documents.

10. Operational Control / Emergency Preparedness.

11. Incident Investigation.

12. Monitoring, Audit and Review.

\subsection{Development of the Methodology}

It was decided to develop and use such a maturity model to measure progress in the integration of the safety management system standards at sites. Here, the "systems" and "culture" elements, that were separate in the Hudson, MIRM and Anglo American models, would be integrated within each of the 12 standards, which is unlike any of the safety maturity models described so far. The Maturity Model, which was named the UK Coal Journey Model, is shown in Figure 4.

Figure 4. UK Coal journey model.

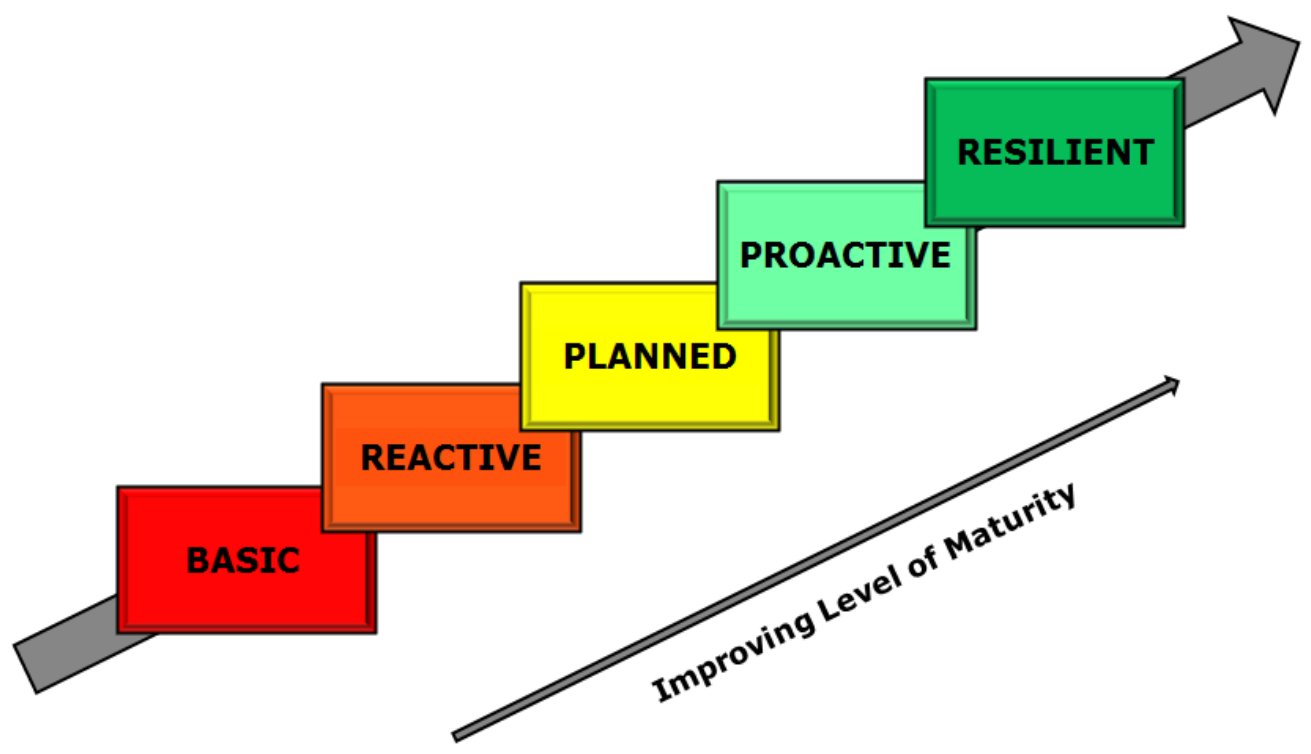


The model was developed so that the bottom level has few or no standards in place, and as a site moves up thorough the five levels they should start to see more of the requirements of the standards in place and there is improved compliance with, and effectiveness of these standards. There is also increased ownership of the standards by Manager, Supervisors and Operators. It should be noted that when examining the measurement system it was important that this could be applied at various levels within the organization. It was also important that there was not a sole reliance on the views of Management, but the process was also able to capture the Workforce views when forming a picture. This would come down to the way the model was applied at sites through team based "self-assessments".

When developing the model it was also felt that it was important to recognize that different sites will invariably be at different places on the UK Coal Journey Model, and it was equally possible that the same sites may be stronger in some of the areas covered by the standards than others. Therefore one of the significant differences here is that the steps are seen as overlapping on the model.

The model was designed not to be an audit tool as such, but to take each standard, and look at how each standard is implemented and what occurs in practice. A self-assessment question set was developed to allow sites to determine their level of maturity (or how far they are "on the journey") by making observations for each standard at each of the 5 levels. From this, sites can look at what areas they need to improve, and then put together a specific action plan to help them move up a level.

As the model was starting to be developed it became very apparent following consultation with the senior management team with that the questions needed to be wide ranging in order to achieve the overall aim of each standard. As a result it was not possible to put together one description or one question per standard. To ensure that all of the implied requirements were met some standards in the model had to have up to four individual descriptions/question sets. The total number of questions/descriptions and their related subjects are shown in Table 2.

A separate "journey improvement" section was also documented, listing suggested actions and initiatives that could be undertaken for each element moving up each of the four stages ("Basic" to "Reactive", "Reactive" to "Planned", "Planned" to "Proactive", "Proactive" to "Resilient"). This was so that each Site could identify actions that they could implement, based on their findings, to move them up a level of maturity, or to move elements that were perhaps lower than the average, up to the average maturity level. As with any maturity model it is not possible for an organization to jump or skip a level, and also to realize that moving up a level can take some considerable time.

Table 2. UK Coal maturity model question set.

\begin{tabular}{ll}
\hline UK Coal Safety Way Element & Question Set \\
\hline 1. Leadership \& Accountability & 1. Safety Leadership \& Commitment \\
& 2. Safety Management Adoption \\
& 3. Rewards of Good Safety Performance \\
& 4. Work Planning \\
& 1. Safety Accountability \\
2. Policy \& Commitment & 2. Safety vs. Production \\
& 3. Safety Responsibilities \\
& 4. Size \& Status of Safety Department \\
& 1. Major Hazard Risk Management \\
3. Risk \& Change Management & 2. Work Site JSA \\
\hline
\end{tabular}


Table 2. Cont.

\begin{tabular}{ll}
\hline UK Coal Safety Way Element & Question Set \\
\hline 4. Legal Requirements & 1. Awareness of Legal Requirements \\
5. Objectives, Targets \& Performance Measurement & 1. Setting of Targets \\
& 2. Monitoring \& Accountability \\
6. Training, Competence \& Awareness & 1. Training \& Competency \\
7. Communication \& Consultation & 2. Assessment of Training \\
& 1. Communications \\
8. Control of Documents & 2. Workforce Involvement \& Consultation \\
9. Operational Controls & 1. Document Control \\
& 1. Jobs planning \& Procedures \\
& 2. Control Measures \& Corrective Actions \\
& 3. Maintenance \\
10. Emergency Procedures & 4. Daily Inspections \\
& 1. Standard of Emergency Planning \\
11. Incident Investigation & 2. Maintaining \& Monitoring Response \\
& 1. Accident Investigation \\
& 2, Quality of Investigations \\
3. Follow up \& Analysis \\
12. Monitoring, Auditing \& Reviews & 4. Hazard \& Unsafe Act Reporting \\
& 1. Safety Performance Measurements \\
\end{tabular}

\subsection{Trialing the Methodology}

The descriptions and questions sets within the model were drafted and in order to test or "calibrate" the model an informal exercise was undertaken at one of the deep mines in January 2011. Following this some of the language and descriptions within the question sets were changed, but it was agreed that the overriding description for each element question set at each stage of maturity was accurate. This was then put together in a workbook so that it could be used at sites. A copy of the question set for Element 5 of the safety management system (Objectives, Targets and Performance Measurement) is shown in Table 3. This shows the two question sets relating to this standard covering (i) the setting of targets and (ii) monitoring and accountability. The overall requirements for this element are as follows.

1. Each site shall establish a measurable safety plan, quantifying corporate objectives and targets and site objectives and targets which shall be agreed by site personnel and corporate personnel. Objectives and targets shall be in line with the general target of enabling continual improvement of health and safety performance.

2. Measurement against the plan shall form part of the site and corporate safety accountability process.

3. Objectives and targets shall be communicated and understood by all appropriate personnel, including the Executive, Senior Management, line management, employees and contractors.

4. Adequate resources shall be assigned to ensure that the planned and agreed targets and objectives are met. 
5. Senior management shall be issued with Safety Performance Indicators. Safety performance shall be part of those indicators to ensure that safety is a priority for management.

6. UK Coal shall ensure that objectives and targets are reviewed on a periodic basis to ensure they stay on programme and to agree changes when they do not.

7. Targets and objectives shall be both reactive-accidents, incidents and dangerous occurrences - and proactive - near hits, etc. and where appropriate, performance measures including benchmarking against established best practice.

8. The organisation and all sites will be responsible for the effective review of objectives, targets and performance indicators to ensure they remain relevant for the current safety risk.

Table 3. Example of question-set related to UK Coal safety way element 5.

\begin{tabular}{|c|c|c|c|c|}
\hline Basic & Reactive & Planned & Proactive & Resilient \\
\hline \multicolumn{5}{|l|}{ 5.1. Setting of Targets } \\
\hline $\begin{array}{l}\text { Little evidence of safety } \\
\text { related activities. Formal } \\
\text { safety goals and objectives } \\
\text { have not been identified, } \\
\text { let alone documented. }\end{array}$ & $\begin{array}{l}\text { Safety goals are based } \\
\text { around improving safety } \\
\text { performance, based on } \\
\text { statistics from the } \\
\text { previous year. } \\
\text { This is set site-wide with } \\
\text { a site plan established by } \\
\text { the safety department that } \\
\text { is passed around the senior } \\
\text { management team, but } \\
\text { not well communicated } \\
\text { to the rest of the } \\
\text { workforce. }\end{array}$ & $\begin{array}{l}\text { Some safety targets } \\
\text { related to improving } \\
\text { standards or systems are } \\
\text { undertaken, but actions } \\
\text { for this mainly apply to } \\
\text { the safety department. } \\
\text { All targets are determined } \\
\text { by the Safety department } \\
\text { and sanctioned by Senior } \\
\text { Management. }\end{array}$ & $\begin{array}{l}\text { Senior Managers are } \\
\text { involved in determining } \\
\text { safety objectives in } \\
\text { conjunction with the } \\
\text { safety department }\end{array}$ & $\begin{array}{l}\text { Every worker in the } \\
\text { organization is } \\
\text { accountable for specific } \\
\text { risk control activities. } \\
\text { Roles and activities are } \\
\text { clearly defined for all } \\
\text { levels in the site. } \\
\text { Work teams } \\
\text { independently establish } \\
\text { their own work } \\
\text { objectives. }\end{array}$ \\
\hline \multicolumn{5}{|c|}{ 5.2. Monitoring \& Accountability } \\
\hline $\begin{array}{l}\text { There is no accountability } \\
\text { as nothing has been set. }\end{array}$ & $\begin{array}{l}\text { Accountability is weak } \\
\text { and progress is rarely } \\
\text { reviewed throughout the } \\
\text { year but the safety } \\
\text { department is held } \\
\text { accountable for results. }\end{array}$ & $\begin{array}{l}\text { Monitoring is carried out } \\
\text { by the Safety department } \\
\text { who also becomes } \\
\text { accountable for actions } \\
\text { and activities related to } \\
\text { the safety management } \\
\text { system. } \\
\text { Accountability is split } \\
\text { between safety and line } \\
\text { management depending } \\
\text { on the results. }\end{array}$ & $\begin{array}{l}\text { Line managers and } \\
\text { supervisors are held } \\
\text { accountable for results. } \\
\text { Safety initiatives/ } \\
\text { activities are adequately } \\
\text { resourced and action } \\
\text { plans/ objectives are set } \\
\text { and monitored. }\end{array}$ & $\begin{array}{l}\text { The safety performance } \\
\text { indicators are proactive, } \\
\text { and a performance } \\
\text { monitoring system is in } \\
\text { place focusing on } \\
\text { operational excellence. }\end{array}$ \\
\hline
\end{tabular}

The baseline studies at the three deep mines were undertaken in April 2011. There was some variation in the makeup of teams at sites with one site's management team initially undertaking the exercise, and at other sites teams consisting of managers, supervisors and operators were brought together. In some cases teams were formed that represented individual parts of the mine (such as the coal preparation plant and the production face). 
The results from each of the exercises were collated and presented on a "spider diagram". Figure 5 shows two such diagrams from one of the mines (Mine A). Where there were differences in maturity noted within elements for different questions, a mean position was taken for the purpose of the diagram. In the diagram the acronyms S1 to S12 represent the 12 elements of the management system as listed in Table 2. Figure 5a shows the results of the original assessment undertaken by the Management Team at Mine A, and Figure 5b shows the combined results for a series of later studies undertaken by groups with Management, Supervisors and Operators within the same mine.

Figure 5. Spider diagram of results from Mine A.

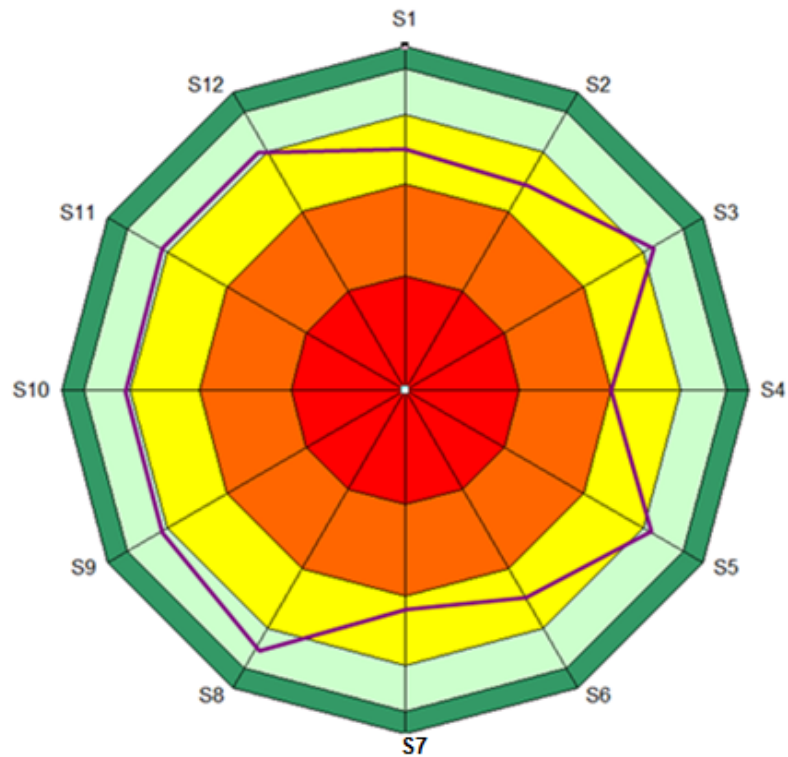

(a)

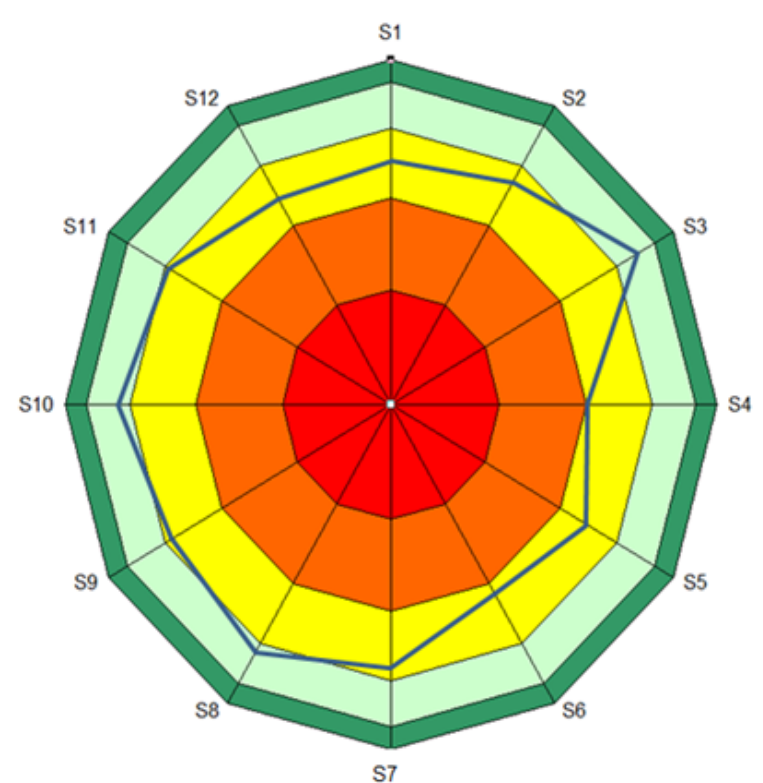

(b)

It can be immediately seen that there is close mapping between the two in terms of weaker and stronger areas despite the studies being undertaken separately at different times and by different people. It can also be seen that there were no elements that were deemed to be resilient (the outer layer in the diagram). Elements 3, 5 and 8-12 were found to be at the "Lower Proactive" level with the remainder in the "Planned" level. This showed that the "doing" and "checking" part of the management system were strong, and that other elements (such as, 1. Leadership/Accountability and 2. Policy/Commitment) were weaker.

In terms of across the three deep mines as a whole, Table 4 shows the percentage of responses for each of the Management system elements across the five levels of maturity for the initial studies at the three sites (A, B and C). 
Table 4. Analysis of results from the deep mines.

\begin{tabular}{lccccc}
\hline \multicolumn{1}{c}{ Element } & Basic & Reactive & Planned & Proactive & Resilient \\
\hline 1. Leadership \& Accountability & - & $8 \%$ & $50 \%$ & $38 \%$ & $4 \%$ \\
2. Policy \& Commitment & - & $8 \%$ & $50 \%$ & $42 \%$ & - \\
3. Risk \& Change Management & - & - & $33 \%$ & $42 \%$ & $25 \%$ \\
4. Legal Requirements & - & $33 \%$ & $50 \%$ & $17 \%$ & - \\
5. Objectives \& Perf Measurement & - & - & $58 \%$ & $42 \%$ & - \\
6. Training, Competence \& Awareness & - & - & $75 \%$ & $17 \%$ & $8 \%$ \\
7. Communication \& Consultation & - & - & $42 \%$ & $58 \%$ & - \\
8. Control of Documents & - & - & $17 \%$ & $83 \%$ & - \\
9. Operational Controls & - & - & $33 \%$ & $63 \%$ & $4 \%$ \\
10. Emergency Procedures & - & - & $17 \%$ & $58 \%$ & $25 \%$ \\
11. Incident Investigation & - & - & $50 \%$ & $37 \%$ & $13 \%$ \\
12. Monitoring, Auditing \& Reviews & - & $8 \%$ & $42 \%$ & $50 \%$ & - \\
\hline
\end{tabular}

It can be seen that some specific elements of the other two deep mines were seen to be "Resilient" by the groups undertaking the exercise. For example, $25 \%$ of the total responses across the sites put Element 3 (Risk and Change Management) and element 10 (Emergency Procedures) at this level. For Element 3, this was mainly down to the specific question set relating to "Work Site Job Safety Analysis" reflecting a well-established process at the mines to undertake task based risk assessments which would then be used to develop a method statement for the specific task. Although the hazards and control measures identified in these assessments were very generic, the mines had got into the process of regularly using these assessments or thinking about them before a task started. This was seen to be doing its job in reinforcing safety at the start of a specific routine task.

In terms of Element 10 (Emergency planning) this score emphasizes the detailed plans in place for dealing with the realization of major mining hazards. At one mine, this plan had been successfully used in late 2010 to successfully evacuate all the workers from underground following a significant ignition of methane gas in one of their gate roads.

By applying this type of process any areas of weakness across the company can be identified, and actions taken centrally to improve them. The individual sites can form plans to start improving their individual areas of weakness and, where there is overlap, work together. At Mine A improvement plans were produced by the Management Team after the initial study at to specifically improve elements 1, 2, 4 and 7 (all of which were in the "Planned" level) to bring them up to the mean of the 12 elements ("Low Proactive"). A summary of this plan is shown in Table 5.

The Journey Model has been used successfully to measure the current "baseline" as the new safety management standards are introduced. The intention is to run the exercise again across the surface and deep mine business with a view to informing the safety intervention strategy for the following year, both on site and as a Company, and to see whether there has been specific improvements from the initial study. In a drive to capture the broadest view and best inform the plan the exercise will continue be run with groups of Operational Managers, Supervisors and Site Operatives. The ultimate intention is to expand the use of this model, using it routinely for audit as well as developing it to measure individual business functions or even individuals within those functions. 
Table 5. Action plan from Mine A.

\begin{tabular}{|c|c|c|c|c|}
\hline Standard/Element & Required Changes & Specific Actions & As Measured by & Responsibility \\
\hline $\begin{array}{l}\text { 1. Leadership \& Accountability } \\
\text { (1.3 Rewards of Good Safety } \\
\text { Performance) }\end{array}$ & $\begin{array}{l}\text { Promote/celebrate significant } \\
\text { safety achievements. }\end{array}$ & $\begin{array}{l}\text { Newsletter } \\
\text { Screen in concourse. }\end{array}$ & $\begin{array}{l}\text { Accident free stats } \\
\text { Specific Work Standards } \\
\text { Achievements }\end{array}$ & $\begin{array}{l}\text { Safety Department } \\
\text { Line Management } \\
\text { HR Manager }\end{array}$ \\
\hline $\begin{array}{l}\text { 2. Policy \& Commitment } \\
\text { (2.1 Safety Accountability) }\end{array}$ & $\begin{array}{l}\text { Utilize front line supervisors } \\
\text { to drive safety and "buy in" } \\
\text { to safety. }\end{array}$ & $\begin{array}{l}\text { Managers Weekly } \\
\text { Meeting with Officials } \\
\text { Engineers weekly meeting } \\
\text { Safety Accountability } \\
\text { meeting }\end{array}$ & $\begin{array}{l}\text { Observation } \\
\text { Auditing }\end{array}$ & Line Management \\
\hline $\begin{array}{l}\text { 2. Policy \& Commitment } \\
\text { ( } 2.4 \text { Status of the Safety Function) }\end{array}$ & $\begin{array}{l}\text { Clearer defined roles and } \\
\text { responsibilities plus } \\
\text { expectations within the } \\
\text { mine management structure }\end{array}$ & $\begin{array}{l}\text { HQ/Colliery Manager } \\
\text { consultation } \\
\text { Align to UK Coal Safety } \\
\text { Policy }\end{array}$ & $\begin{array}{l}\text { Compliance to Colliery } \\
\text { Safety Action Plan }\end{array}$ & HQ/Colliery Manager \\
\hline $\begin{array}{l}\text { 4. Legal Requirements } \\
\text { (4.1 Awareness of Legal } \\
\text { Requirements) }\end{array}$ & $\begin{array}{l}\text { HQ Informing all line } \\
\text { management in new/changes } \\
\text { to legislation }\end{array}$ & $\begin{array}{l}\text { Email line managers } \\
\text { bulletin with changes } \\
\text { to legislation } \\
\text { Refresher updates for line } \\
\text { management (away } \\
\text { from pit) }\end{array}$ & $\begin{array}{l}\text { Compliance to all legislation, } \\
\text { company directives \& codes } \\
\& \text { rules }\end{array}$ & HQ/Colliery Manager \\
\hline $\begin{array}{l}\text { 7. Communication \& Consultation } \\
\text { (1. Communications) }\end{array}$ & $\begin{array}{l}\text { Two way communication } \\
\text { between management \& } \\
\text { workforce }\end{array}$ & $\begin{array}{l}\text { Face \& Development start } \\
\text { up meetings } \\
\text { All other meetings }\end{array}$ & $\begin{array}{l}\text { Testing Knowledge } \\
\text { Observations }\end{array}$ & Line Management \\
\hline
\end{tabular}

\section{Conclusions}

The Maturity model concept has already, through the work of Hudson and Fleming, been shown to be a useful tool for organizations to establish their levels of safety culture maturity. The model here differs in that it is directly linked to a Company's own safety management standards and any cultural elements have been defined within this. It has been successfully used by teams of Managers, Supervisors and Workers to look at the maturity of the safety management system at their sites. Likening the maturity to a "journey" also helps make the model more practical and friendlier to use. Whilst ultimately sites would like to move forward together on the journey, it does recognize that different sites will be at different places, and it is often important at the early stage of any improvement that any weaker areas be targeted first.

\section{Acknowledgements}

The Authors would like to thank UK Coal and the work teams involved in the initial exercises at the mine sites. The views expressed in this paper are those of the authors.

\section{References and Notes}

1. Fleming, M. Safety Culture Maturity Model; HSE Offshore Technology Report 2000/049: Sudbury, UK, 2000; pp. 3-7. 
2. Hudson, P. Implementing a safety culture in a major multi-national. Safety Sci. 2007, 45, 697-722.

3. Gordon, R.; Kirwan, B.; Perrin, E. Measuring safety culture in a research \& development centre: A comparison of two methods in the air traffic management domain. Safety Sci. 2007, 45, 669-695.

4. Keil Centre. Managing Safety Culture in the UK Rail Industry: Report on the Review of Safety Culture Tools and Methods; Rail Safety \& Standards Board: London, UK, 2004.

5. Kyriakidis, M.; Hirsch, R.; Majumdar, A. Metro railway safety: An analysis of accident precursors. Safety Sci. 2012, 50, 1535-1548.

6. Lardner, R. Towards a Mature Safety Culture. Presented at the Institute of Chemical Engineers Annual Conference, Manchester, UK, 2002.

7. Filho, A.P.G.; Andrade, J.C.S.; de Oliveira Marinho, M.M. A safety culture maturity model for petrochemical companies in Brazil. Safety Sci. 2010, 48, 615-624.

8. Fleming, M.; Lardner, R. Safety culture-The way forward. Chem. Eng. 1999, 689, 16-18.

9. Hudson, P. Applying the lessons of high risk industries to health care. Qual. Saf. Health Care 2003, 12, i7-i12.

10. Parker, D.; Lawrie, M.; Hudson, P. A framework for understanding the development of organisational safety culture. Safety Sci. 2006, 44, 551-562.

11. Reducing Error and Influencing Behavior, 2nd ed.; Health and Safety Executive: Sudbury, UK, 1999.

12. Changing Minds: A Practical Guide for Behavioural Change in the Oil \& Gas Industry. Step Change in Safety Website. Available online: http://www.stepchangeinsafety.net/knowledgecentre/ publications/publication.cfm/publicationid/16 (accessed on 14 November 2012)

13. Department of Resources, Energy \& Tourism. Leading Practice Sustainable Development Practice for the Mining Industry: Risk Assessment \& Management; Commonwealth of Australia: Canberra, Australia, 2008; pp. 15-16.

14. Joy, J. Minerals Industry Safety \& Health Centre, University of Queensland. Personal Communication, 2011.

15. The University of Queensland, Minerals Industry Risk Management Maturity Chart. University of Queensland Minerals Industry Health \& Safety Centre: Brisbane, Australia, 2008.

16. Detailed Journey Workbook, part of the A3 Safety Risk Management Process Training Material, Internal Document. Anglo American Plc: London, UK, 2010.

17. UK Coal Plc. Annual Reports \& Accounts 2011. Available online: http://coalfieldresources.com/uploads/assets/pdf/625_ukcoalplc2011bookmarked.pdf (accessed on 22 January 2013).

(C) 2013 by the authors; licensee MDPI, Basel, Switzerland. This article is an open access article distributed under the terms and conditions of the Creative Commons Attribution license (http://creativecommons.org/licenses/by/3.0/). 